\title{
Analysis of the Proliferative Potential of Odontogenic Epithelial Cells of Pericoronal Follicles
}

\author{
${ }^{1}$ Natalia Cimadon, ${ }^{2}$ Isabel Silva Lauxen, ${ }^{3}$ Vinicius Coelho Carrard, ${ }^{4}$ Manoel Sant'Ana Filho \\ ${ }^{5}$ Pantelis Varvaki Rados, ${ }^{6}$ Márcia Gaiger Oliveira
}

\section{ABSTRACT}

Aim: To evaluate the proliferative potential and the cell proliferation rate of odontogenic epithelial cells.

Materials and methods: Forty-two cases of pericoronal follicles of impacted third molars were submitted to silver impregnation technique for quantification of argyrophilic nucleolar organizer regions (AgNOR) and immunohistochemical staining for EGFR and $\mathrm{Ki}-67$. For AgNOR quantification, the mean number of active nucleolar organizer regions per nucleus ( $\mathrm{mAgNOR}$ ) and the percentage of cells with 1,2, 3 and 4 or more AgNORs per nucleus (pAgNOR) were quantified. Ki-67 immunolabeling was quantified, whereas for EGFR, a descriptive analysis of staining patterns (membrane, cytoplasm or membrane + cytoplasm positivity) was performed. We evaluated the reduced epithelium of the enamel organ and/or islands of odontogenic epithelium present in the entire connective tissue.

Results: mAgNOR were 1.43 (1.0-2.42) and were significantly different among pericoronary follicles from upper and lower teeth $(p=0.041)$. Immunostaining of $\mathrm{Ki}-67$ was negative in all cases. EGFR immunolabeling was found mainly in the cytoplasm and was more intense in islands and cords when compared to reduced epithelium of the enamel organ.

Conclusion: Odontogenic epithelial cells of some pericoronal follicles have proliferative potential, suggesting their association with the development of odontogenic lesions

Clinical significance: The authors suggest that nonerupted, especially of the lower teeth, should be monitored and if necessary removed.

Keywords: Cell proliferation, Odontogenic, Pericoronal follicles, Laboratory research.

How to cite this article: Cimadon N, Lauxen IS, Carrard VC, Filho MSA, Rados PV, Oliveira MG. Analysis of the Proliferative Potential of Odontogenic Epithelial Cells of Pericoronal Follicles. J Contemp Dent Pract 2014;15(6):761-765.

Source of support: Nil

Conflict of interest: None

${ }^{1-6}$ Department of Oral Pathology, School of Dentistry Universidade Federal do Rio Grande do Sul, Porto Alegre RS, Brazil

Corresponding Author: Márcia Gaiger Oliveira, Professor Department of Oral Pathology, School of Dentistry Universidade Federal do Rio Grande do Sul, Rua Ramiro Barcelos, 2492/503 Porto Alegre, RS, 90035-003, Brazil, e-mail: marciago@ gmail.com

\section{INTRODUCTION}

The pericoronal follicle is a structure that covers the crown of impacted teeth. Histologically, it is characterized by connective tissue and varying amounts of epithelium remaining from odontogenesis, in the form of islands, cords and/or reduced epithelium of the enamel organ. ${ }^{1}$

The literature discusses the prevalence of cysts and tumors development associated with impacted teeth. For some authors, the development potential of pericoronal tissue damage is real and increases with age, and this is a factor to be taken into account when treating impacted teeth. ${ }^{2-7}$ Other authors consider that the development of lesions from the epithelium of unerupted teeth is rare and does not justify the removal of this tissue. ${ }^{8,9}$

AgNOR is a technique of silver impregnation of active nucleolar organizer regions (NORs). AgNOR are proteins associated with the synthesis of ribosomal RNA directly related to the rate of cell proliferation. The quantification of AgNORs allow inferring the speed with which the cells proliferate. ${ }^{10}$

$\mathrm{Ki}-67$ is a nuclear antigen present in the active phases of the cell cycle. Immunodetection of this protein is considered an indicator of cell proliferation and it is used to measure the percentage of cells proliferating in a given tissue. $^{11}$

Another factor associated with epithelial cell proliferation is the epidermal growth factor (EGF) and its receptor EGFR. The cell compartment where this receptor informs how it will respond to a proliferative stimulus: (a) expression of the receptor in the membrane and cytoplasm indicates cells at a physiological proliferation rate, (b) receptor expressed only in the membrane occurs in cells highly responsive to the proliferative stimulus, and (c) presence of the receptor only in the cytoplasm shows that it is internalized or inactive, which may indicate a slower response. The presence and location of the EGFR in odontogenic epithelium may be related to the origin of odontogenic cysts and tumors. ${ }^{12,15}$

The proliferative potential and the capacity of odontogenic epithelial cells to produce odontogenic cysts and tumors are not yet fully elucidated. Studies have shown that there are differences in the proliferative potential of odontogenic epithelial cells and that this fact may 
be decisive in the formation of odontogenic cysts and tumors. ${ }^{5-15}$

When studying epithelial rests in the connective wall of pericoronal follicles and dentigerous cysts, Meleti and Van der Waal ${ }^{16}$ found three cases in which islands of odontogenic epithelium were frankly arranged in an ameloblastoma-like morphological pattern. These cases were called 'focal ameloblastomas', suggesting that their early transformation from pericoronal follicles into ameloblastomas.

The aim of the present study was to evaluate the proliferative potential and the cell proliferation rate of odontogenic epithelial cells by immunostaining of Ki-67 and EGFR, as well as to measure AgNORs and to investigate a possible relationship with the development of odontogenic cysts and tumors.

\section{MATERIALS AND METHODS}

The study was approved by the local Ethics and Research Committee.

The sample was selected from cases with clinical diagnosis of pericoronary follicle and the material was from completely impacted teeth $(n=256)$ received by the Laboratory of Oral Pathology of School of Dentistry in a period of 10 years $(n=256)$. Inclusion criteria were the absence or presence of minimal inflammatory infiltrate and the presence of odontogenic epithelium in the form of reduced epithelium of the enamel organ and/or islands and cords of odontogenic epithelium. We excluded case that showed stratified epithelium featuring dentigerous cyst $^{17}$ and cases with negligible amount of odontogenic epithelium, thus remaining 42 cases. Data on age, sex and origin of the pericoronal (upper or lower) follicle were obtained from biopsy records.

From each paraffin block $4 \mu \mathrm{m}$ cuts were made, which were submitted to different techniques: hematoxylin and eosin (HE) staining, silver impregnation for evaluating AgNOR by Ploton et $\mathrm{al}^{10}$ protocol, and Ki-67 and EGFR immunodetection.

\section{IMMUNOHISTOCHEMISTRY}

Sections were deparaffinized in xylene and rehydrated in alcohol. Endogenous peroxidase activity was blocked using $3 \%$ hydrogen peroxide in methanol in two 15 minutes baths. Antigen retrieval was performed using a low-pH retrieval solution (S1699, DakoCytomation, Carpinteria, CA, USA) in a microwave oven for 20 minutes (four 5 minutes cycles) for $\mathrm{Ki}-67$ and in a pressure cooker ( 2 cycles: $121^{\circ} \mathrm{C}-3 \mathrm{~min}$ and $90^{\circ} \mathrm{C}-30 \mathrm{sec}$ ) for EGFR. Subsequently, sections were incubated for 60 minutes at room temperature with each marker as follow: Ki-67 (1:50, clone MIB1, Dako Cytomation, Carpinteria, CA, USA) and EGFR (1:30, Clone EGFR 113, Novocastra, Newcastle, UK); and then washed in phosphate buffered saline (PBS). The detection system used was Envision $+\circledR$ (DakoCytomation, Carpinteria, CA, USA) and the chromogen was liquid diaminobenzidine (DakoCytomation, Carpinteria, CA, USA). Sections were rinsed, counterstained with Harris hematoxylin, rehydrated and cleared in xylene; slides were mounted in Permount (Fisher Scientific, Fair Lawn, NJ, USA). Sections of oral squamous cell carcinoma were used for positive control and negative controls were obtained by omission of the primary antibody.

Morphological analysis and amount of epithelium were evaluated in the HE-stained slides, and pictures from all tissue were made at a 400× magnification. From each sample undergoing AgNOR technique, all histological fields containing odontogenic epithelium were captured at 1000× magnification in immersion oil, and had the number of AgNORs per nucleus (Fig. 1) counted with Image ${ }^{\circledR}$ software (National Institutes of Health, Bethesda, MD, USA). Mean of AgNORs (mAgNOR) and the percentage of cells with 1, 2, 3, 4 or more AgNORs per nucleus (pAgNOR) were calculated.

From the samples that were subjected to immunohistochemistry for Ki-67 and EGFR, all histological fields containing odontogenic epithelium were captured at 400x magnification. Odontogenic epithelial cells with brown staining, regardless of intensity, were considered positive. For Ki-67, a quantitative analysis of positive nuclei in all epithelial cells was performed. EGFR immunolabeling was analyzed descriptively, i.e. concerning presence and location of staining (cytoplasm, membrane, or cytoplasm + membrane) in each field. A histological analysis was performed for all fields with regard to the type of odontogenic epithelium present (islands and/or cords, reduced epithelium of the enamel organ or both).

Slides were assessed by three oral pathologists previously calibrated, with acceptable intraobserver and interobserver Kappa values (0.7-1.0).

\section{STATISTICAL ANALYSIS}

Data were analyzed using Fisher's exact test to check the association between qualitative variables; Mann-Whitney and Kruskal-Wallis tests to compare the values of the variables without normal distribution, Student's t-test and analysis of variance to compare variables with normal distribution in their data. For all tests, the maximum significance level assumed was $5 \%(p \leq 0.05)$, and the software used for statistical analysis was SPSS version 10.0. 


\section{RESULTS}

From the samples of 42 pericoronal follicles 30 were from women and 12 from men. Age varied between 13 and 26 years. Mean age was 18.2, ranging from 13 to 26 years. Sixteen cases were from upper teeth and 26 were from lower teeth (Table 1). The morphological analysis of tissues showed that $21.4 \%$ of the follicles had epithelial rests (ER) in the form of nests and cords, $71.4 \%$ had reduced epithelium of the enamel organ (REEO), and 7.1\% had both variations in the same follicle (ER/REEO).

The AgNOR technique resulted in an overall mean (mAgNOR) of 1.43, with a significant difference between the cases from upper teeth and lower teeth (Table 2). Graph 1 shows the distribution of mAgNOR for each case, in relation to the final mean.

The percentage of active nucleolus organizer regions (pAgNOR) showed no significant difference among the groups (Table 2).

Ki-67 immunostaining was negative in all cases. EGFR immunostaining was positive in $86 \%$ of the analyzed fields, distributed among membrane (4\%), cytoplasm (70.31\%), and cytoplasm + membrane (10.71\%). The epithelial islands and cords showed higher positivity for EGFR than the reduced epithelium of the enamel organ. Among the epithelial nests and cords, $71.07 \%$ of the cells were positive for EGFR, while $28.93 \%$ of the cells of the reduced epithelium were marked.

Table 1: Sample profile

\begin{tabular}{lll}
\hline & $N$ & Percentage (\%) \\
\hline Age & & \\
$13-18$ & 26 & 61.90 \\
$19-26$ & 16 & 38.09 \\
Sex & & \\
Female & 30 & 71.42 \\
Male & 12 & 28.57 \\
Location & & \\
Upper teeth & 16 & 38.09 \\
Lower teeth & 26 & 61.90 \\
\hline
\end{tabular}

Table 2: $\mathrm{mAgNOR}$ and $\mathrm{pAgNOR}$ values according to teeth location

\begin{tabular}{llll}
\hline Location & $\begin{array}{l}\text { Upper teeth }(n \\
=16) \\
\text { Mean }(S D)\end{array}$ & $\begin{array}{l}\text { Lower teeth } \\
(n=26) \\
\text { Mean }(S D)\end{array}$ & $p$ \\
\hline mAgNOR & $1.31(0.14)$ & $1.51(0.36)$ & $0.041^{*}$ \\
pAgNOR = 1 & $72.78(12.12)$ & $64.45(20.33)$ & 0.104 \\
pAgNOR = 2 & $22.96(10.77)$ & $24.84(11.99)$ & 0.612 \\
pAgNOR = 3 & $3.85(3.36)$ & $8.30(11.20)$ & 0.243 \\
pAgNOR $\geq 4$ & $0.32(0.62)$ & $2.46(7.23)$ & 0.431 \\
\hline
\end{tabular}

*ANOVA: Analysis of variance; SD: Standard deviation

\section{DISCUSSION}

The maintenance of impacted teeth and their respective pericoronal tissues might be related to the formation of odontogenic cysts and tumors. However, the etiopathogenesis of odontogenic cysts and tumors is unclear. Some studies suggest that the odontogenic epithelial cells found in the follicle might have potential to cause odontogenic lesions. ${ }^{5,15-18}$

The need to remove all impacted third molars is debatable. The occurrence of lesions associated with impacted third molars varies among studies ${ }^{16-20}$ Nordenram et $\mathrm{al}^{19}$ show $4.5 \%$ of the cases and Bruce et $\mathrm{al}^{20}$ reported $6.2 \%$ of cases.

Many studies have shown that the amount of AgNORs is directly related to the speed of proliferation.,21,22 The overall mAgNOR was 1.43, similar to the average found in some studies for dentigerous cysts, ${ }^{15-23}$ corresponding to low proliferation rate. This average is lower than the average reported for odontogenic tumors like ameloblastoma and keratocystic odontogenic tumor. ${ }^{24-26 .}$

In the present study, two cases in particular showed mAgNOR values near 2.5 (Fig. 1), showing that they had the highest proliferation speed. In these two cases, the follicles located in the mandible were in the 19 to 26 years range. Considering the frequency of cystic and tumoral lesions, it could be speculated that, if not removed, this dental follicles would develop odontogenic cysts and tumors.

We observed that the epithelial cells of the pericoronal follicles showed mAgNOR of 1.31 for upper teeth and 1.51 for lower teeth, significantly differing among them. In addition, although not showing any statistically significant difference, it is worth noting that with a pAgNOR of 3 and 4, or more, follicles from lower teeth showed more significant results when compared to those from upper teeth. This shows that cells from some follicles from lower teeth proliferate more rapidly and are more prone

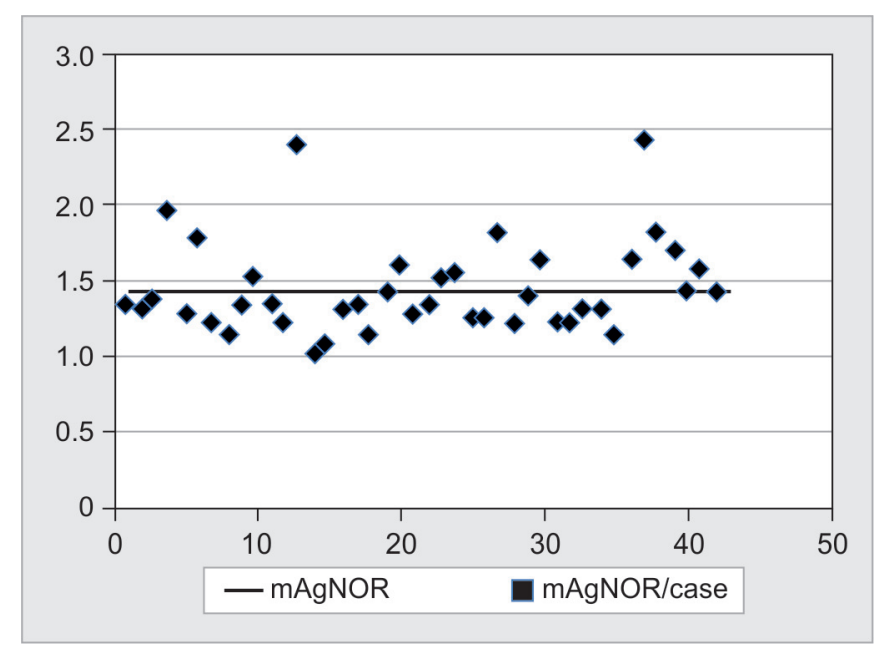

Graph 1: Distribution of mAgNOR values in the sample 


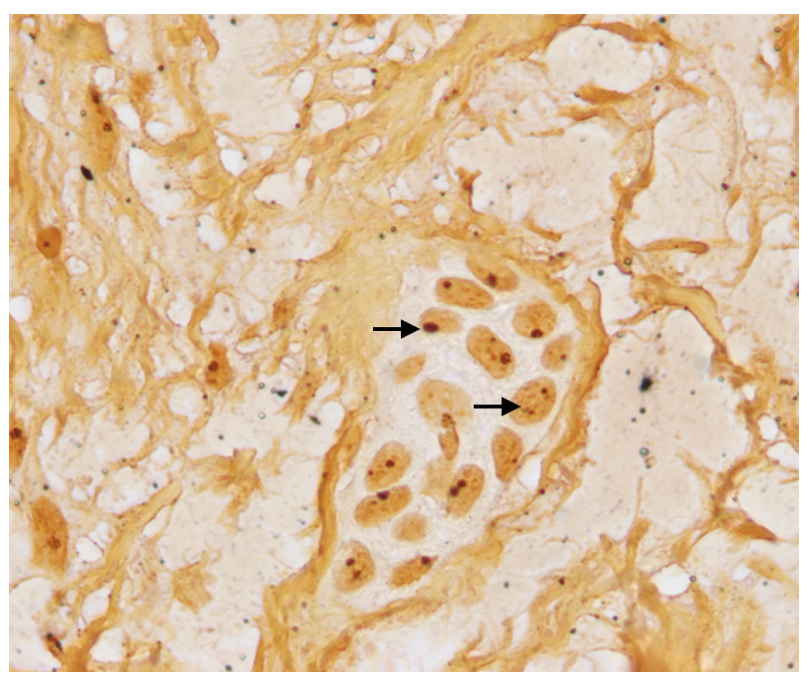

Fig. 1: Nest of epithelial odontogenic cells with argyrophilic nuclear organizer regions dots (arrows) in nucleus (AgNOR stain, original magnification 1000x)

to the development of lesions. These results agree with the literature, i.e. that odontogenic lesions occur mostly in the mandible. ${ }^{27-29}$

The location of the EGFR receptor in the cell appears to be associated with the way in which the cell responds to the proliferative stimulus. ${ }^{12-15}$ In the follicles studied, $70.31 \%$ of immunostaining occurred only in the cytoplasm; this means the receiver has already been activated and internalized by the cell and a reaction to proliferative stimulus is less likely. Staining in the membrane and cytoplasm occurred in $10.71 \%$ of the cases showing a physiological rate of proliferation, since even having already internalized part of its receptors, the cell still has receptors in its membrane. Our results are in agreement with Baumgart et $\mathrm{a}^{15}$ and with the findings of Damjanov et al, ${ }^{12}$ who show that the distribution pattern of EGFR might indicate different response degrees to the proliferative stimulus.

It should be noted that a small portion of the sample $(4 \%)$ showed immunoreactivity only at the cell membrane (Fig. 2), which may indicate that these cells have a higher capacity to proliferate to a stimulus since the receptors are available to bind to the growth factor and this is the pattern found in cells with high proliferative capacity, and this result is in agreement with the frequency of odontogenic tumors.

Between nests and cords of odontogenic epithelial cells and reduced epithelium of the enamel organ, there was a statistically significant difference in the labeling of EGFR. The nests and cords stained positive in $71.07 \%$ of cases, while only $28.93 \%$ of the reduced epithelium was immunostained.

Ki-67 estimates the number of cells in phase G1, S, $\mathrm{G} 2$ and $\mathrm{M}$ and does not detect the cells in $\mathrm{G} 0 .{ }^{13} \mathrm{~S}$ Ki-67 immunostaining was negative in the follicles analyzed,

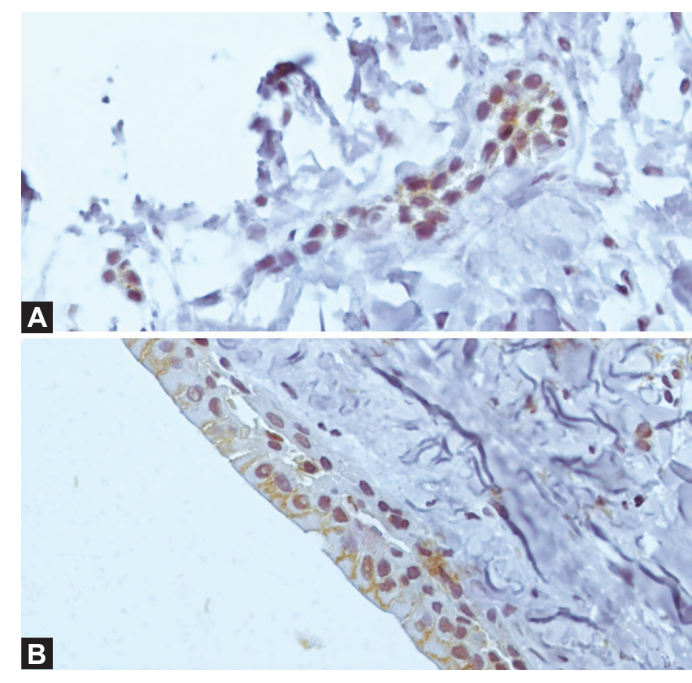

Figs 2A and B: (A) Nests and cords of odontogenic epithelial cells and $(B)$ reduced epithelium of the enamel organ showing immunoreactivity only at the cell membrane (anti-EGFR stain, original magnification 400x)

this means the cells are in the G0 phase, i.e. in the latency phase. However, this marker only reports the number of cells that are proliferating (growth fraction) and not how fast they are proliferating (proliferation rate). Therefore, the analyses EGFR and AgNOR together complement these results.

Güler et $\mathrm{al}^{30}$ found positivity for Ki-67 in the epithelium of pericoronal follicles and this positivity was linked to morphological alterations such as squamous metaplasia and the presence of inflammatory cells. In our study, cases with squamous metaplasia of the reduced epithelium of the enamel organ and the presence of inflammatory infiltrate were excluded from the sample, which might justify the negativity of Ki-67.

In a study by Oliveira et $\mathrm{al}^{31}$ a higher percentage of Ki-67 immunostaining was found in odontogenic keratocystic tumors than in pericoronal follicles and dentigerous cysts. In addition, they observed that the pericoronal follicles had higher reactivity to EGFR than to Ki-67. This result is similar to those found in the present study, which showed an $86 \%$ positivity of the analyzed fields to EGFR and negativity for Ki-67 in the entire sample.

Our results in AgNOR and expression of EGFR show that, in general, the epithelial cells of the pericoronal follicles are quiescent with low capacity to respond to a proliferative stimulus. However, some of these cells showed proliferation potential, particularly those located in the mandible, which is the most prevalent location for odontogenic lesions. This is a remarkable finding, since odontogenic cysts and tumors are more frequent in the mandible than in the maxilla.

These data suggest that epithelial cells of pericoronal follicles are involved in the formation of odontogenic cysts and tumors and reinforce the need for complete 
removal of the follicle during surgery, since the possibility of developing odontogenic tumors increases and might explain the development of odontogenic neoplasms in adulthood.

\section{CONCLUSION AND CLINICAL SIGNIFICANCES}

Based on the data obtained in the present study, the authors suggest that nonerupted teeth, especially the lower teeth, should be monitored and if necessary removed.

\section{REFERENCES}

1. Kramer IR, Pindborg JJ, Shear M. The WHO histological typing of odontogenic tumors. A commentary on the second edition. Cancer 1992;70(12):2988-2994.

2. Girod SC, Gerlach KL, Kreuger G. Cysts associated with long-standing third molars. Int J Oral Maxillofac Surg 1993; 22(2):110-112.

3. Kahl B, gerlach KL, Hilgers RD. A long-term follow-up radiographic evaluation of asymptomatic impacted third molars in orthodontically treated patients. Int J Oral Maxillofac Surg 1994;23(5):279-285.

4. Van der Linden W, Cleaton-Jones P, Lownie M. Diseases and lesions associated with third molars: review of 1001 cases. Oral Surg Oral Med Oral Pathol Oral Radiol Endod 1995; 79(2):142-145.

5. Curran AE, Damm DD, Drummond JF. Pathologically significant pericoronal lesions in adults: histopathologic evaluation. J Oral Maxillofac Surg 2002;60(6):613-617.

6. Brkić A, Mutlu S, Koçak-Berberoğlu H, Olgaç V. Pathological changes and immunoexpression of p63 gene in dental follicles of asymptomatic impacted lower third molars: an immunohistochemical study. J Craniofac Surg 2010;21(3):854-857.

7. Costa FWG, Viana TSA, Cavalcante GM, Silva PGB, Nogueira AS, Pereira KMA. A clinicoradiographic and pathological study of pericoronal follicles associated to mandibular third molars. J Cranifac Surg 2014;25(3):e283-287.

8. Saraçoğlu U, Kurt B, Günhan O, Güven B. MIB-1 expression in odontogenic epithelial rests, epithelium of health oral mucosa and epithelium of selected odontogenic cysts: na immunohistochemical study. Int J Oral Maxillofac Surg 2005; 34(4):432-435.

9. Villalba L,StobizerF, BlascoF,MaurinoNR, PiloniMJ,Keszler A. Pericoronal follicles of asymptomatic impacted teeth: a radiographic, histomorphologic, and immunohistochemical study. Int J Dent 2012;(2012):955310.

10. Ploton D, Menager M, Jeannesson P, Himber G, Pigeon F, Adnett JJ. Improvement in the staining and in the visualization of the argyrophilic proteins of the nucleolarorganiser regions at the optical level. Histochem J 1986;18(1):5-14.

11. Jalava P, Kuopiot T, Juntti-Patinem L, Kotkansalo T, Kronquist P, Collan Y. Ki-67 immunohistochemistry: a valuable marker in prognostication but with a risk of misclassification: proliferation subgroups formed based on Ki-67 immunoreactivity and standardized mitotic index. Histopathology 2006;48(6):674-682.

12. Damjanov I, Mildner B, Knowles BB. Immunohistochemical localization of the epidermal growth factor receptor in normal human tissues. Lab Invest 1986;55(5):588-592.

13. Gulkesen KH, Kilicarslan B, Altunbas HA, Karpuzoglu G. EGFR and p53 expression and proliferative activity in parathyroid adenomas; an immunohistochemical study. APMIS 2001;109(12):870-874.

14. Herbst RS. Review of epidermal growth factor receptor biology. Int J Radiol Oncol Biol Phys 2004;59(2 suppl):21-26.

15. Baumgart CS, Lauxen IS, Sant'AnaFilho M, Quadros OF. Epidermal growth factor receptor distribution in pericoronal follicles: relationship with the origin of odontogenic cysts and tumors. Oral Surg Oral Med Oral Pathol Oral Radiol Endod 2007;103(2):240-245.

16. Meleti M, van der Waal I. Clinicopathological evaluation of 164 dental follicles and dentigerous cysts with emphasis on the presence of odontogenic epithelium in the connective tissue. The hypothesis of 'focal ameloblastoma'. Med Oral Patol Oral Cir Bucal 2013;18(1):e60-64.

17. Glosser JW, Campbell JH. Pathologic change in soft tissues associated with radiographically 'normal' third molar impactions. Br J Oral Maxill Surg 1999;37(4):259-260.

18. Saravana GHL, Subhashraj K. Cystic changes in dental follicle associated with radiographically normal impacted mandibular third molar. Br J Oral Maxillofac Surg 2008;46(7):552-553.

19. Nordenram A, Hultin M, Kjellman O, Ramstrom G. Indications for surgical removal of the mandibular third molar. Swed Dent J 1987;11(1-2):23-29.

20. Bruce RA, Frederickson GC, Small GS. Age of patients and morbidity associated with mandibular third molar surgery. J Am Dent Assoc 1980;101(2):240-245.

21. Derenzini M, Trerè D, Pession A, Montanaro L, Sirri V, Ochs RL. Nucleolar function and size in cancer cells. Am J Pathol 1998;152(5):1291-1297.

22. Derenzini M, Trerè D, Pession A, Govoni M, Sirri V, Chieco P. Nucleolar size indicates the rapidity of cell proliferation in cancer tissues. J Pathol 2000;191(2):181-186.

23. Coleman HG, Altini M, Groeneveld HT. Nucleolar organizer regions (AgNORs) in odontogenic cysts and ameloblastomas. J Oral Pathol Med 1996;25(8):436-440.

24. Eslami B, Yaghmaei M, Firoozi M, Saffar AS. Nucleolar organizer regions in selected odontogenic lesions. Oral Surg Oral Med Oral Pathol Oral Radiol Endod 2003;95(2):187-192.

25. Gadbail AR, Chaudhary M, Patil S, Gawande M. Actual proliferating index and $\mathrm{p} 53$ protein expression as prognostic marker in odontogenic cysts. Oral Dis 2009;15(7):490-498.

26. Seifi S, Shafigh E, Allaie A. Quantitative and qualitative analysis of argyrophilic nuclear organizer regions in follicular cyst, keratocystic odontogenic tumor and ameloblastoma. J Cancer Res Ther 2011;7(3):280-285.

27. Prockt AP, Schebela CR, Maito FDM, Sant'Ana-Filho M, Rados PV. Odontogenic Cysts: Analysis of 680 Cases in Brazil. Head and Neck Pathol 2008;2(3):150-156.

28. Rodrigues TLC, Rodrigues FG, Carodos AB, Gandelmann IHA, Cavalcante MAA. Benign tumors of the jaws: a 10-year retrospective analysis. Rev Cir Traumatol Buco Maxillofac 2010;10(1):91-96.

29. Santos JN, Pinto LP, Figueiredo CRLV, Souza LB. Odontogenic tumors: analysis of 127 cases. Pesqui Odontol Bras 2001; 15(4):308-313.

30. Güler N, Çomunoğlu N, Cabbar F. Ki-67 and MCM2 in dental follicle and odontogenic cysts: the effects of inflammation on proliferative markers. Scientific World J 2012;(2012):946060.

31. Oliveira MG, Lauxen IS, Chaves ACM, Rados PV, Sant'AnnaFilho M. Odontogenic epithelium: immunolabeling of Ki-67, EGFR and Survivin in Pericoronal Follicles, Dentigerous Cysts and Keratocystic Odontogenic Tumors. Head Neck Pathol 2011;5(1):1-7. 